
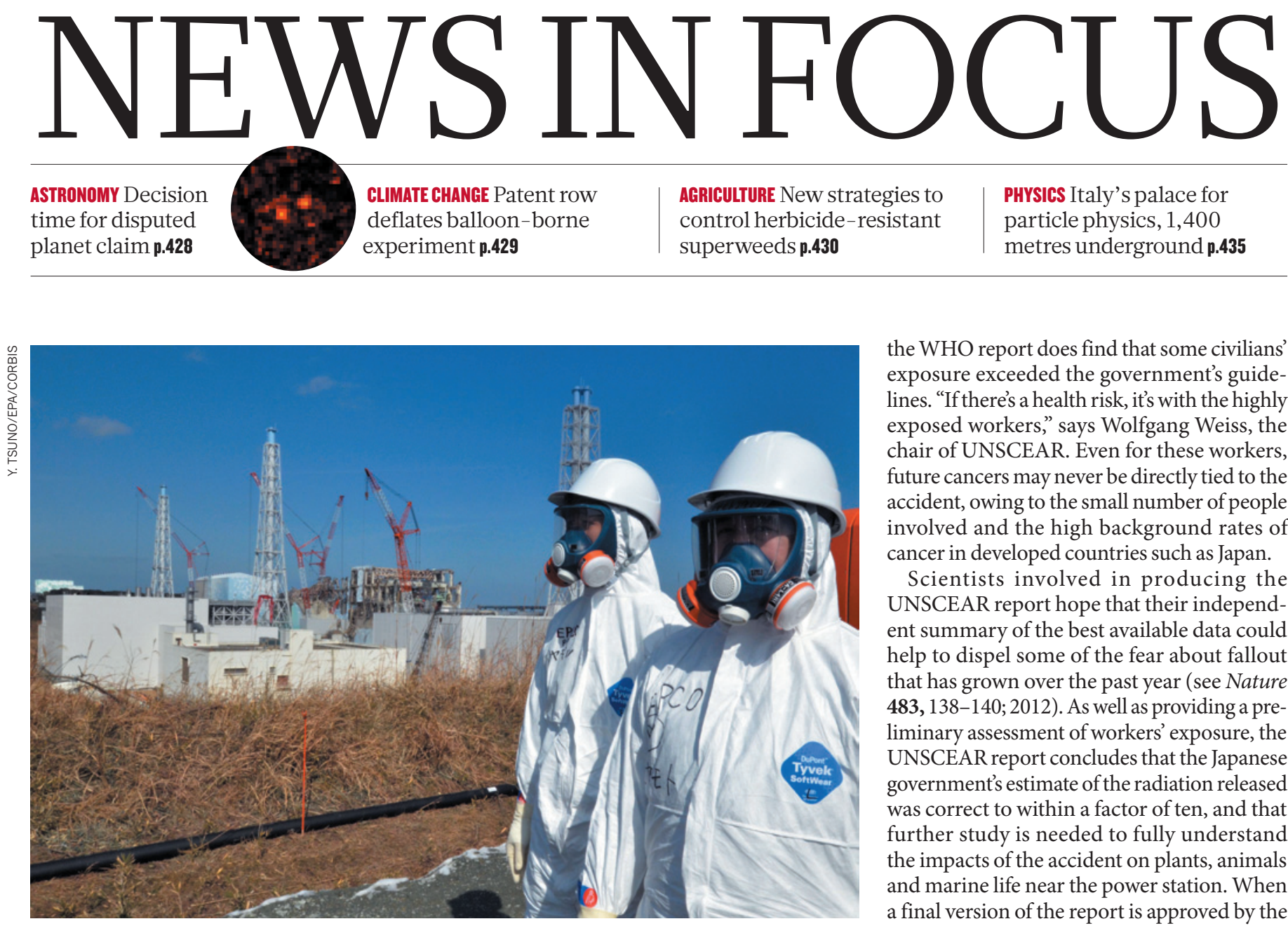

Around 170 of Fukushima's workers have a slightly elevated risk of cancer due to their radiation exposure.

\title{
RADIATION HEALTH
}

\section{Fukushima's doses tallied}

\section{Studies indicate minimal health risks from radiation in the aftermath of Japan's nuclear disaster.}

\section{BY GEOFF BRUMFIEL}

$\mathrm{F}$ ew people will develop cancer as a consequence of being exposed to the radioactive material that spewed from Japan's Fukushima Daiichi nuclear power plant last year - and those who do will never know for sure what caused their disease. These conclusions are based on two comprehensive, independent assessments of the radiation doses received by Japanese citizens, as well as by the thousands of workers who battled to bring the shattered nuclear reactors under control.

The first report, seen exclusively by Nature, was produced by a subcommittee of the United
Nations Scientific Committee on the Effects of Atomic Radiation (UNSCEAR) in Vienna, and covers a wide swathe of issues related to all aspects of the accident. The second, a draft of which has been seen by Nature, comes from the World Health Organization (WHO) in Geneva, Switzerland, and estimates doses received by the general public in the first year after the accident. Both reports will be discussed at UNSCEAR's annual meeting in Vienna this week.

The UNSCEAR committee's analyses show that 167 workers at the plant received radiation doses that slightly raise their risk of developing cancer. The general public was largely protected by being promptly evacuated, although

the WHO report does find that some civilians' exposure exceeded the government's guidelines. "If there's a health risk, it's with the highly exposed workers," says Wolfgang Weiss, the chair of UNSCEAR. Even for these workers, future cancers may never be directly tied to the accident, owing to the small number of people involved and the high background rates of cancer in developed countries such as Japan.

Scientists involved in producing the UNSCEAR report hope that their independent summary of the best available data could help to dispel some of the fear about fallout that has grown over the past year (see Nature 483, 138-140; 2012). As well as providing a preliminary assessment of workers' exposure, the UNSCEAR report concludes that the Japanese government's estimate of the radiation released was correct to within a factor of ten, and that further study is needed to fully understand the impacts of the accident on plants, animals and marine life near the power station. When a final version of the report is approved by the full UNSCEAR committee next year, it should provide a useful baseline for future studies.

The Fukushima crisis began on 11 March 2011, when a magnitude-9.0 earthquake triggered a tsunami off the coast of Japan. A 14-metre wave flooded four of the six reactors at the Fukushima Daiichi plant, knocking out emergency cooling systems and leading to meltdowns and explosions that released radioactivity into the air and ocean. In the year since the accident, the plant has been stabilized, and radioactive emissions have largely stopped.

From last autumn, UNSCEAR has been reviewing all the available data on Fukushima's radiation - just as it did to produce what was then the definitive report on the 1986 Chernobyl nuclear accident. In particular, it scoured anonymized medical data for 20,115 workers and contractors employed by the Tokyo Electric Power Company, which runs the plant. It found that 146 employees and 21 contractors received a dose of more than 100 millisieverts ( $\mathrm{mSv}$ ), the level at which there is an acknowledged slight

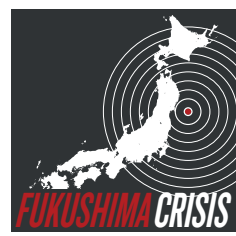

$\rightarrow$ WWW.NATURE. COM/JAPANQUAKE increase in cancer risk. Six workers received more than the $250 \mathrm{mSv}$ allowed by Japanese law for front-line emergency workers, and two operators in the control rooms for reactor units 3 and 4 received doses above 


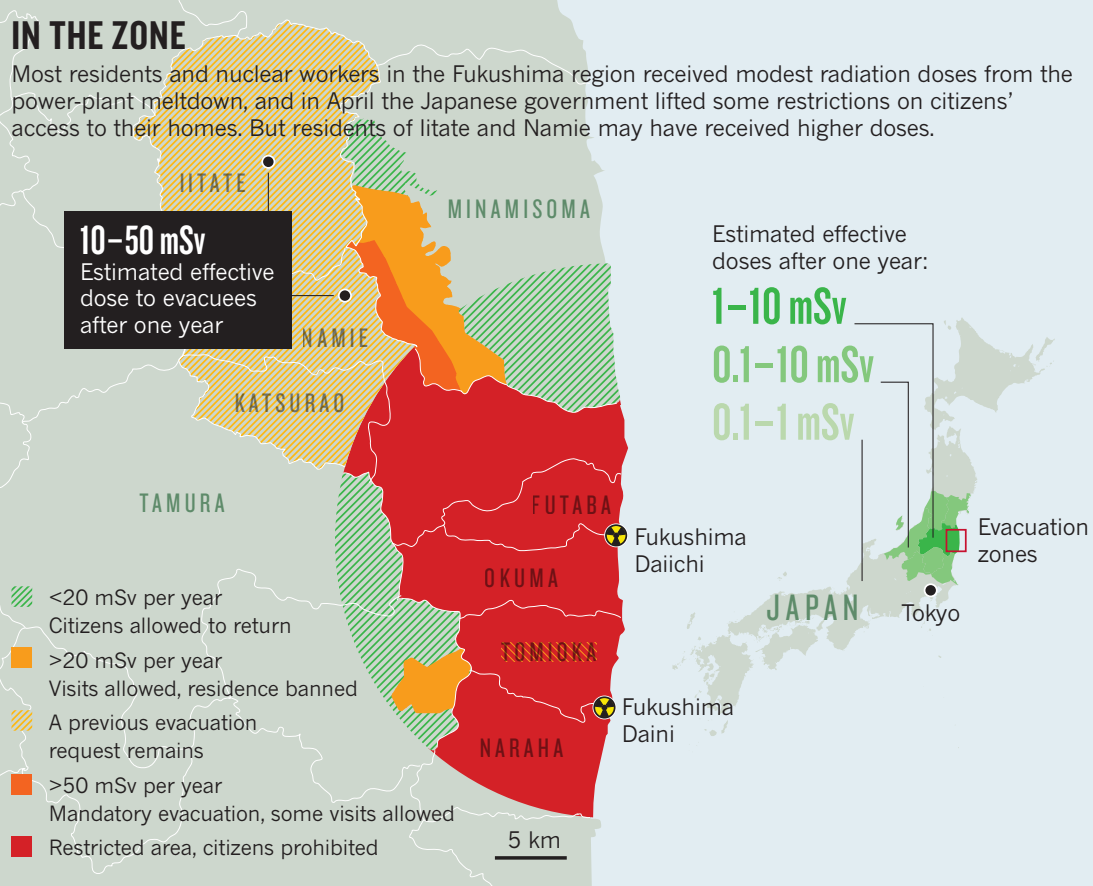

\section{FUKUSHIMA PLANT-WORKER DOSES}

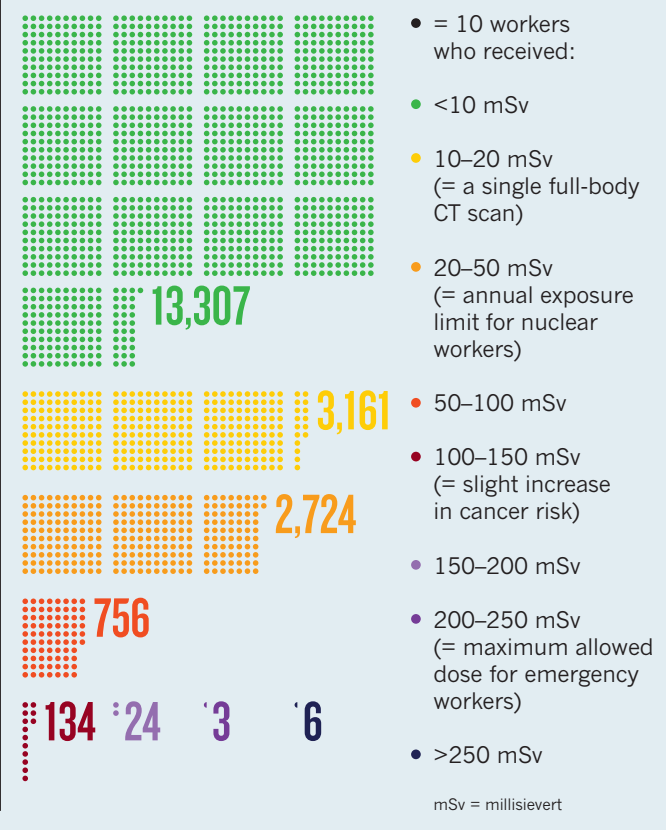

$600 \mathrm{mSv}$, because they had not taken potassium iodide tablets to help prevent their bodies from absorbing radioactive iodine-131 (see 'In the zone'). So far, neither operator seems to have suffered ill effects as a result of their exposure.

Most of the workers who received high doses were exposed in the early days of the crisis. In those first hours, they were huddled in darkened control rooms, while small teams made forays inside the reactor buildings to survey the damage and manually operate valves and other equipment. Often, they did not know how much radiation was present - the report says that an automated system designed to monitor their radiation levels was not operating properly. By mid-April, basic access control and monitoring had been restored on the site.

Experts agree that there is unlikely to be a detectable rise in thyroid cancer or leukaemia, the two cancers most likely to result from the accident. "There may be some increase in cancer risk that may not be detectable statistically," says Kiyohiko Mabuchi, who heads Chernobyl studies at the National Cancer Institute in Rockville, Maryland. In Chernobyl, where clean-up workers were exposed to much higher doses, $0.1 \%$ of the 110,000 workers surveyed have so far developed leukaemia, although not all of those cases resulted from the accident.

The risk to the roughly 140,000 civilians who had been living within a few tens of kilometres of the plant seems even lower. Because detailed radiation measurements were unavailable at the time of the accident, the WHO estimated doses to the public, including radiation exposure from inhalation, ingestion and fallout. The agency concludes that most residents of Fukushima and neighbouring Japanese prefectures received a dose below $10 \mathrm{mSv}$. Residents of Namie town and Iitate village, two areas that were not evacuated until months after the accident, received 10-50 mSv. The government aims to keep public exposure from the accident below $20 \mathrm{mSv}$ per year, but in the longer term it wants to decontaminate the region so that residents will receive no more than $1 \mathrm{mSv}$ per year from the accident.

The WHO's calculations are consistent with several health surveys conducted by Japanese scientists, which found civilian doses at or below the 1-15-mSv range, even among people living near the plant. One worrying exception is that infants in Namie town may have been exposed to enough iodine-131 to receive an estimated thyroid dose of 100-200 mSv, raising their risk of thyroid cancer. But data collected from 1,080 children in the region found that none had received a thyroid dose greater than $50 \mathrm{mSv}$. Chernobyl's main cancer legacy in children was thyroid cancer.

\section{FEARFUL AND ANGRY}

The large population involved could mean that the eventual number of radiation-induced cancers among the public will actually be higher than among workers, even though the risk to each individual civilian is tiny, says David Brenner, a radiologist at Columbia University in New York city. But he doubts a direct link will ever be definitively made. Under normal circumstances, " $40 \%$ of everybody will get cancer", he says. "It doesn't seem to me that it's possible to do an epidemiological study that will see an increased risk." Still, it may be valuable to conduct studies to reassure the population that they are not being misled, he adds.

A far greater health risk may come from the psychological stress created by the earthquake, tsunami and nuclear disaster. After Chernobyl, evacuees were more likely to experience posttraumatic stress disorder (PTSD) than the population as a whole, according to Evelyn Bromet, a psychiatric epidemiologist at the State University of New York, Stony Brook. The risk may be even greater at Fukushima. "I've never seen PTSD questionnaires like this," she says of a survey being conducted by Fukushima Medical University. People are "utterly fearful and deeply angry. There's nobody that they trust any more for information."

Overall, the reports do lend credibility to the Japanese government's actions immediately after the accident. Shunichi Yamashita, a researcher at Fukushima Medical University who is heading one local health survey, hopes that the findings will help to reduce stress among victims of the accident. But they may not be enough to rebuild trust between the government and local residents. Tatsuhiko Kodama, head of the radioisotope centre at the University of Tokyo and an outspoken critic of the government, questions the reports' value. "I think international organizations should stop making hasty reports based on very short visits to Japan that don't allow them to see what is happening locally," he says.

UNSCEAR's working committee of roughly 70 scientists still has much to do before the final report is completed. Committee members will continue to independently validate sources of data from the accident and work on models of the flow of radioisotopes from the reactors into the environment. For the workers, "individual medical follow-up is more important than the statistical follow-up", Weiss says. "People want to know whether what we say is true." - SEE EDITORIAL P.415

Additional reporting by Rina Nozawa. 